\title{
Single-Port Laparoscopic Appendectomy Performing by Emergency Operation: An Intervention Study in Vietnam
}

\author{
Duc Minh Pham ${ }^{1}$, Vu Anh Pham ${ }^{1}$, Mai Tuyet $\mathrm{Vi}^{2}$ and Linh Van Pham ${ }^{3, *}$ \\ ${ }^{1}$ Hue University of Medicine and Pharmacy, Hue University, Hue, Vietnam \\ ${ }^{2}$ Faculty of Pharmacy, Can Tho University of Medicine and Pharmacy, Can Tho, Vietnam \\ ${ }^{3}$ Hong Bang International University, Ho Chi Minh, Vietnam \\ "Corresponding author: Hong Bang International University, Ho Chi Minh, Vietnam. Tel: +84-913425422, Email: pvlinh@ctump.edu.vn
}

Received 2021 August 22; Revised 2021 October 17; Accepted 2021 October 17.

\begin{abstract}
Background: Appendectomy is one of the most commonly performed surgical procedures of the abdominal area. One of the recent innovations is single-port laparoscopic surgery (SPLS), which can insert multiple ports through a proprietary device with multiple channels. An incision is sited in the umbilicus to result in no visible scar.

Objectives: The study aimed to evaluate the results of the treatment of acute appendicitis by applying single-port laparoscopic surgery.

Methods: A clinical single-port laparoscopic appendectomy intervention of 122 patients, with the absence of a control group, was carried out by a sole surgeon at the Hue University of Medicine and Pharmacy Hospital, Hue, Vietnam, from August 2013 to December 2017. Research parameters included clinical history, physical examination, laboratory test, ultrasound imaging, intraoperative characteristics, and surgical outcomes.

Results: We included 122 patients (64 males and 58 females) who met the inclusion criteria. The mean age was $31.28 \pm 13.51$ years (range, 16 - 73 years). The average BMI was $20.4 \pm 1.39 \mathrm{~kg} / \mathrm{m}^{2}$. All patients had abdominal pain, and the average duration of symptoms was $17.39 \pm 5.41$ hours (range, 6 - 31 hours). Five patients had a history of abdominal surgery. The mean diameter of appendicitis in ultrasound was $8.8 \mathrm{~mm}$ (range, $6-15 \mathrm{~mm}$ ). Moreover, 89.3\% of patients had an increase in white blood cells. The difficult location of appendicitis was $1.6 \%$ under the liver and $20.5 \%$ in the retrocecal region. In addition, $18.0 \%$ of retroperitoneal appendicitis and $6.6 \%$ of appendicitis were under cecalserosa. The mean operative time was $40.19 \pm 14.67 \mathrm{mins}$ (range, $23-150 \mathrm{~min}$ ). Two cases (1.6\%) required additional trocar insertion. Three cases $(2.5 \%)$ had wound infection and no other complications. The median hospital stay was $3.64 \pm 1.72$ days (range, 2 - 13 days).

Conclusions: Single-port laparoscopic surgery is the safe and effective treatment of acute appendicitis. This technique may be feasible for acute appendicitis with a difficult location.
\end{abstract}

Keywords: Appendicitis, Single-Port Laparoscopy, Vietnam

\section{Background}

Appendectomy is one of the most commonly performed surgical procedures of the abdominal area $(1,2)$. Laparoscopic surgery is the preferred technique widely accepted by many surgeons as the standard gold therapy for treating acute appendicitis due to its reduced postoperative pain, more rapid recovery, and improved cosmesis (3). Following the concept of minimally invasive surgery, surgeons put in efforts to fully utilize the advantages of laparoscopic surgery by reducing the number of incisions that would bring the benefits of improving cosmetic appearance and reducing abdominal wall trauma. One of the recent innovations is single-port laparoscopic surgery (SPLS), which can insert multiple ports through a propri- etary device with multiple channels. An incision is sited in the umbilicus to result in no visible scar (4).

Pelosi performed the first application of single-port laparoscopic appendectomy (SPLA) in 1992 (5). Many surgeons showed the new approach is safe and used to perform a large variety of procedures, including cholecystectomy, splenectomy, and colon resection $(6,7)$. In 2019, three-port laparoscopic appendectomy (TPLA) was compared to SPLA and found feasibility and highly safe by Tomoe Moriguchi (Japan) (8). In addition, SPLA has been studied in many countries with different types of patients, from adults to children, with desirable results (9). Besides, SPLA has been studied in many countries with different patients, from adults to children, with desirable results (10- 
12).

The conflict of instruments, absence of triangulation, and difficult retraction of mesoappendix are the main technical issues for SPLA. Recently, advances in laparoscopic instruments and optical systems have enabled surgeons to perform this technique. SPLA still has some significant limits of the surgical field and difficult access to the operation through a small incision (13). It requires more experience with surgical cases and more skill, experience in emergency cases. However, few data and studies on the risk have been established, and no definite indication criteria for SPLA application $(4,14)$.

Nowadays, single-port laparoscopic appendectomy (SPLA) is a new treatment in many countries (15). In Vietnam, the research on evaluating the feasibility, safety, and clinical advantage of the single-port laparoscopic appendectomy method with conventional instruments is an important means of transferring this method to hospitals. Therefore, we aimed to evaluate the treatment results of acute appendicitis by applying single-port laparoscopic surgery in Vietnam.

\section{Objectives}

The study aimed to evaluate the results of the treatment of acute appendicitis by applying single-port laparoscopic surgery.

\section{Methods}

The study evaluated 122 patients who underwent single-port laparoscopic appendectomy for acute appendicitis treatment at Hue University of Medicine and Pharmacy Hospital, Viet Nam, from August 2013 to December 2017. The routine preoperative examinations included complete surgical history, physical examination, laboratory blood count, and abdominal ultrasonography. Individuals who were pregnant or younger than 16 years of age were excluded from the study cohort. Patients who had septic shock, peritonitis, or previous surgery through the umbilical region were also excluded. All cases were performed by a single surgeon.

\subsection{Surgical Technique}

Each patient was subjected to general anesthesia and placed in the supine position with the left arm alongside the body. The surgeon and medical assistants were on the patient's left side, and the laparoscopy monitor was on the patient's right side.
Before the skin drape, the umbilicus was cleansed with betadine solution. An umbilical incision of $20 \mathrm{~mm}$ was performed by pulling the umbilicus with two Allis forceps under direct vision. The single-port device (SILS ${ }^{\mathrm{TM}}$ Port $12 \mathrm{~mm}$, Covidien, USA) was inserted from this defect. The SILS port is a foam plug inserted through a $20-\mathrm{mm}$ fascial incision, which is once inserted to retract the abdominal wall and prevent air leakage. Pneumoperitoneum was initiated to a pressure of $12 \mathrm{mmHg}$. The operating table was tilted to the Trendelenburg position.

The conventional laparoscopic instruments used to perform the procedure were a $30^{\circ} 10-\mathrm{mm}$ laparoscopic camera, dissector, grasper, and scissor (Olympus Medical Systems). The laparoscope camera was utilized to visualize the operative field. A 5-mm grasper was inserted through the port for retracting the appendix. A dissector was used for the dissection along the border of the mesoappendix to the appendiceal base. The control of the appendiceal artery has been achieved by using coagulation. After the ligation of the appendiceal base performed by using a Vicryl 2.0 intracorporeal knot-tying, the appendix was sharply divided. The mucosa of the appendix stump was cauterized. The appendix and single-port device were slowly retrieved. One layer interrupt suture was done to the peritoneum and fascia with a Vicryl 1.0. The subcutaneous layer was repaired by an interrupted suture using Vicryl 3.0.

\subsection{Data Collection and Analysis}

Participants were assessed preoperatively to confirm eligibility, and perioperative data were collected. The following parameters were collected on the patients preoperatively: (1) age, (2) body mass index (BMI), (3) time from onset to hospitalization, (4) history, (5) white blood cell (WBC) counts, and (6) abdominal ultrasound. The intraoperative characteristics of acute appendicitis were classified according to their location and involvement of adjacent organs.

The primary clinical outcome was evaluated by the severity of pain, using the visual analogue scale (VAS) at 1 - 7 days. Other clinical outcomes included the duration of operation (minutes), complication rates, conversion rates, and duration of hospitalization (days). The longterm follow-up duration was set at six months.

\subsection{Statistical Analysis}

The results were collected into a database and analyzed by using the SPSS.20 application. Data were expressed by number and percentage as well as by mean and standard deviation (SD). The statistical significance was confirmed with the P-values $<0.05$. 


\subsection{Ethics Considerations}

The study was approved by the Medical Ethics Council of Hue University of Medicine and Pharmacy. Information of participating patients was kept confidential.

\section{Results}

\subsection{Epidemiological Characteristics}

The study included 58 women and 64 men with a mean age of $31.28 \pm 13.51$ years (16 - 73 years). The average BMI was $20.38 \pm 1.39 \mathrm{~kg} / \mathrm{m}^{2}$, ranging from 16.9 to $24.7 \mathrm{~kg} / \mathrm{m}^{2}$. All patients had abdominal pain, and the average duration of symptoms was $17.39 \pm 5.41$ hours (range, 6 - 31 hours).

\subsection{Intra-Operative Characteristics of Acute Appendicitis}

Five patients had a history of abdominal surgery, including one left inguinal hernia procedure, two cesarean sections, one sterilization, and one resection of giant ovarian tumor. The mean diameter of appendicitis by ultrasound was $8.8 \mathrm{~mm}$ (range, $6-15 \mathrm{~mm}$ ) and $89.3 \%$ of patients had increased levels of white blood cells. The intraoperative characteristics of acute appendicitis were classified according to their location and involvement of adjacent organs (Table 1).

\begin{tabular}{|lc|}
\hline Table 1. Intra-Operative Characteristics of Acute Appendicitis & \\
\hline Intraoperative Finding & No. $(\%)$; $=\mathbf{1 2 2}$ \\
\hline Location of appendix & $111(91.0)$ \\
\hline Right iliac fossa & $2(1.6)$ \\
\hline Under the liver & $9(7.4)$ \\
\hline Right pelvis & \\
\hline Appendiceal location with cecum and ileum & $80(65.6)$ \\
\hline Subcecum & $25(20.5)$ \\
\hline Retrocecum & $7(5.7)$ \\
\hline Paracecum & $10(8.2)$ \\
\hline Postileum & \\
\hline Involvement of adjacent organs & $7(5.7)$ \\
\hline Appendix covered by greater omentum & $10(8.2)$ \\
\hline Appendix covered with ileum & $8(6.6)$ \\
\hline Appendix under cecal serosa & $22(18.0)$ \\
\hline Retroperitoneal appendix &
\end{tabular}

\subsection{Postoperative Outcomes of Single-Port Laparoscopic Ap- pendectomy}

The mean of the operative time was $40.19 \pm 14.67$ minutes (range, 23 - 150 minutes). There was no intraabdominal injury or massive bleeding during the operation. Of the 122 patients, two cases required an additional trocar insertion. There were no patients who required conversion to conventional laparoscopic appendectomy or open appendectomy (Table 2).

\begin{tabular}{lcc}
\hline \multicolumn{2}{l}{ Table 2. Postoperative Outcomes of Single-Port Laparoscopic Appendectomy } \\
\hline Variable & Mean \pm SD & Range \\
\hline Operative time (min) & $40.19 \pm 14.67$ & $(23-150)$ \\
\hline Pain at 1st POD (VAS) & $4.13 \pm 2.04$ & $(1-9)$ \\
\hline Pain at 2nd POD (VAS) & $2.67 \pm 1.75$ & $(1-9)$ \\
\hline Pain at 7th POD (VAS) & $1.18 \pm 0.60$ & $(1-5)$ \\
\hline Time until gas passing (h) & $13.11 \pm 5.53$ & $(6-36)$ \\
\hline Time until starting diet $(\mathbf{h})$ & $16.34 \pm 6.94$ & $(8-51)$ \\
\hline Hospital stay (day) & $3.64 \pm 1.72$ & $(2-13)$ \\
\hline
\end{tabular}

Abbreviations: VAS, visual analogue scale; POD, postoperative day.

The time of starting a diet after surgery was $16.34 \pm$ 6.94 hours. Postoperative complications occurred in three patients $(2.5 \%)$ with wound complications. These patients were treated by antibiotic therapy. The median hospital stay was $3.64 \pm 1.72$ days (range, 2 - 13 days). On the first day after surgery, the VAS was $4.13 \pm 2.04$. A mean VAS on the second postoperative day was $2.67 \pm 1.75$. All the patients were reexamined on the seventh postoperative day, and no postoperative complication was encountered. The mean of VAS on the seventh postoperative day was $1.18 \pm 0.60$. The long-term follow-up period was six months. Moreover, $81.15 \%$ of patients were followed up for six months, and no patient showed any evidence of complication (Table 2).

\section{Discussion}

The era of minimally invasive surgery has been toward performing operations without a scar. The SPLS has been applied as a new trend in abdominal surgery, which significantly has reduced the number of surgical sites. However, SPLA is not free from difficulties, especially by the loss of triangulation associated with the classic technique, retraction, and dissection of the appendix (16). In addition, SPLA can be challenging in some special cases, such as abnormal location or serious adhesion of appendicitis. In this study, the difficulty in localizing appendicitis was combined by $20.5 \%$ with retrocecum and $1.6 \%$ with under the liver. The feasibility of SPLA is mainly evaluated by the involvement of adjacent organs. Thus, advanced operative skills are vital for this approach. In this study, cases involving organs, including $18 \%$ retroperitoneal appendicitis, $6.6 \%$ appendicitis under cecal serosa, and $8.2 \%$ appendicitis covered with ileum (Table 1), were successfully performed with no intraoperative complication. 
Regarding operating time, some studies have shown that SPLA lasts approximately 2 to 6 minutes longer than conventional laparoscopy, which might have resulted from a lack of experience in using the new technique $(17,18)$. Despite the disadvantage, some surgeons expect that SPLA's effectiveness will eventually reach conventional methods (1). Throughout the study, the mean operating time was $40.19 \pm 14.67$ minutes, with the range of 23 to 150 minutes case being the shortest ( 23 minutes) and the 4 th case being the longest (150 minutes). In the latter case, the appendicitis was located in the subserosa of the cecal wall and was too difficult to operate on.

The average postoperative hospitality was $3.64 \pm 1.72$ days (range of 2 to 13), with three patients of extended duration for wound therapy. In this study, $81.15 \%$ of patients were followed up for six months, and there was no complication reported.

In SPLA therapy, early pain was more severe in comparison to the conventional laparoscopy approach. The cause of elevated pain is widely accepted due to the length of fascia incision being longer than the skin incision in the umbilical area (19). The mean VAS score in this study was 4.13 \pm 2.04 on the first postoperative day. With a low expectation of pain from patients, the unpredictably strong reaction might cause higher VAS on the first day (5). Several authors described the umbilicus as a natural scar without a vessel or nerve $(20,21)$. However, increasing the incision size over the umbilical region would damage the subcutaneous vessels and nerves. In the pain management on the first postoperative day, Lohsiriwat et al. (22) introduced bupivacaine into the muscular layer of the operative site. They found the pain reduction at 6,12 , and 24 postoperative hours. Kim et al. (20) reported that the pain level on the second postoperative day was lower than at the first postoperative day for the group that underwent SPLA and as same as conventional laparoscopy. In our study, the postoperative pain was reevaluated on day 7 with the mean VAS at $1.18 \pm 0.60$ (vs. $2.67 \pm 1.75$ on day 2 ), which was mild and required no pharmacological therapy.

Damaging the epigastric vessels, one of the uncommon complications from laparoscopic appendectomy procedure that may lead to emergencies, could be avoided in applying SPLA (17). In the study of 1,145 cases that underwent SPLS by Weiss et al. (23), the average incision length was $3.77 \pm 1.62 \mathrm{~cm}$ in the group with an incisional hernia and $2.96 \pm 1.06 \mathrm{~cm}$ in the group without the complication. In our study, the incisional length was in the range of 2.0 to $2.5 \mathrm{~cm}$ and could not increase the incisional hernia rate. Of all participants in this study, three patients contracted wound infection, and no one had a major postoperative complication. Weiss et al. (23) reported that removing the surgical specimens was not related to the infection rate; however, preoperative cleaning of umbilical and periumbilical skin would reduce the incidence of postoperative infection.

The SPLA is more technically challenging than conventional laparoscopy, even for experienced surgeons $(24,25)$. There are challenges when this technique is approached rapidly. Ibrahim (25) suggested that SPLA could be applied cautiously and used to perform exploratory surgery. However, the high conversion rate to conventional laparoscopy has been a significant setback of SPLA (1). In the study of Chiu et al. (16), two of 26 cases required the insertion of one additional port, and one of 26 was converted to the common three-port technique. The individuals in these cases had significant bowel distention followed by extensive inflammation and adhesions from perforated appendicitis. Choudhary et al. (6) performed 25 cases using SPLA, two of which must be converted to open procedure due to excessive adhesion. In our study, two cases required an additional trocar insertion: (1) one due to acute appendicitis and excessive adhesion; (2) another retrocecal insertion into the subserosa of the cecal wall. Both of these cases showed difficulties in mobilizing the appendix. Thus, the decision to add an additional trocar was dependent on the difficulty degree of appendicitis. The surgeon, who performed SPLA, was experienced in conventional laparoscopy with complicated appendicitis. However, cases of appendicitis with abscess or phlegmon remained challenging for SPLA. Regarding these cases, we had the indication of performing SPLA when the situation happened within two days. In our study, there was one case of acute appendicitis with dense adhesion; we inserted an additional trocar for the operation afterward.

Based on the results from this study, we believe that the feasibility of single-port laparoscopic appendectomy has provided a new direction for surgeons in clinical application, and the minimally invasive methods on patients are more developed. Improving the SPLA approach, in both technical and accepting aspects, requires more researches. The main limitation of this study was small sample population.

\section{Footnotes}

Authors' Contribution: Study concept and design, D. M. P., V. A. P., and L. V. P.; Analysis and interpretation of data, D. M. P.; Drafting of the manuscript, D. M. P. and M. T. V.; Critical revision of the manuscript for important intellectual content, D. M. P.; Statistical analysis, D. M. P.

Conflict of Interests: The authors declare that there is no conflict of interest. 
Ethical Approval: The study was approved by Hue University of Medicine and Pharmacy with the code 01082013.

Funding/Support: This research received no funding. Informed Consent: It was not declared by the authors.

\section{References}

1. Cai YL, Xiong XZ, Wu SJ, Cheng Y, Lu J, Zhang J, et al. Single-incision laparoscopic appendectomy vs conventional laparoscopic appendectomy: Systematic review and meta-analysis. World J Gastroenterol. 2013;19(31):5165-73. doi: 10.3748/wjg.v19.i31.5165. [PubMed: 23964153]. [PubMed Central: PMC3746391].

2. Sohn M, Agha A, Bremer S, Lehmann KS, Bormann M, Hochrein A. Surgical management of acute appendicitis in adults: A review of current techniques. Int J Surg. 2017;48:232-9. doi: 10.1016/j.ijsu.2017.11.028. [PubMed: 29155250].

3. Malik M, McCormack K, Krukowski ZH, McDonald A, McPherson G, Cook JA, et al. Single port/incision laparoscopic surgery compared with standard three-port laparoscopic surgery for appendicectomy a randomised controlled trial. Trials. 2012;13:201. doi:10.1186/1745-621513-201. [PubMed: 23111090]. [PubMed Central: PMC3543288].

4. Kim SJ, Choi BJ, Lee SC. Novel approach of single-port laparoscopic appendectomy as a solo surgery: A prospective cohort study. Int J Surg. 2015;21:1-7. doi: 10.1016/j.ijsu.2015.07.010. [PubMed: 26192971].

5. Baik SM, Hong KS, Kim YI. A comparison of transumbilical single-port laparoscopic appendectomy and conventional three-port laparoscopic appendectomy: From the diagnosis to the hospital cost. J Korean Surg Soc. 2013;85(2):68-74. doi: 10.4174/jkss.2013.85.2.68. [PubMed: 23908963]. [PubMed Central: PMC3729989].

6. Choudhary KVS, Sinwar PD, Kajla RK, Chouhan SP, Dhukiya R, Bansal P. Study of Feasibility of Single Incision Laparoscopic Appendicectomy (SILA) Using Conventional Instruments. Sch J App Med Sci. 2014;2(5D).

7. Vilallonga R, Barbaros U, Nada A, Sumer A, Demirel T, Fort JM, et al. Single-port transumbilical laparoscopic appendectomy: A preliminary multicentric comparative study in 87 patients with acute appendicitis. Minim Invasive Surg. 2012;2012:492409. doi: 10.1155/2012/492409. [PubMed: 22655190]. [PubMed Central: PMC3359719].

8. Moriguchi T, Machigashira S, Sugita K, Kawano M, Yano K, Onishi $S$, et al. A Randomized Trial to Compare the Conventional ThreePort Laparoscopic Appendectomy Procedure to Single-Incision and One-Puncture Procedure That Was Safe and Feasible, Even for Surgeons in Training.J Laparoendosc Adv Surg Tech A. 2019;29(3):392-5. doi: 10.1089/lap.2018.0195. [PubMed: 30418099].

9. Kang BM, Choi SI, Kim BS, Lee SH. Single-port laparoscopic surgery in uncomplicated acute appendicitis: A randomized controlled trial. Surg Endosc. 2018;32(7):3131-7. doi: 10.1007/s00464-018-6028-0. [PubMed: 29340826].

10. Binet A, Braik K, Lengelle F, Laffon M, Lardy H, Amar S. Laparoscopic one port appendectomy: Evaluation in pediatric surgery. J Pediatr Surg. 2018;53(11):2322-5. doi: 10.1016/j.jpedsurg.2017.12.018. [PubMed: 29370892].

11. Golebiewski A, Anzelewicz S, Wiejek A, Lubacka D, Czauderna P. A Prospective Randomized Controlled Trial of Single-Port and ThreePort Laparoscopic Appendectomy in Children. J Laparoendosc Adv Surg Tech A. 2019;29(5):703-9. doi: 10.1089/lap.2018.0560. [PubMed: 30945979].

12. Jin SG, Cho SH, Kim KY, Ahn SK, Cho J, Jung BW, et al. Transumbilical Single-Incision Laparoscopic-Assisted Appendectomy (TULAA) Is
Useful in Adults and Young Adolescents: Comparison with MultiPort Laparoscopic Appendectomy. Medicina (Kaunas). 2019;55(6). doi: 10.3390/medicina55060248. [PubMed: 31195748]. [PubMed Central: PMC6632055].

13. Kim Y, Lee W. The learning curve of single-port laparoscopic appendectomy performed by emergent operation. World J Emerg Surg. 2016;11:39. doi: 10.1186/s13017-016-0096-z. [PubMed: 27499804]. [PubMed Central: PMC4975885].

14. Choi KW, Park BK, Suh SW, Lee ES, Lee SE, Park JM, et al. Risk factors for additional port insertion in single-port laparoscopic appendectomy. Wideochir Inne Tech Maloinwazyjne. 2019;14(2):223-8. doi: 10.5114/wiitm.2018.77714. [PubMed: 31118987]. [PubMed Central: PMC6528115].

15. Kim SJ, Choi BJ, Jeong W, Lee SC. The feasibility of single-port laparoscopic appendectomy using a solo approach: A comparative study. Ann Surg Treat Res. 2016;90(3):164-70. doi: 10.4174/astr.2016.90.3.164. [PubMed: 26942160]. [PubMed Central: PMC4773461].

16. Chiu CG, Nguyen NH, Bloom SW. Single-incision laparoscopic appendectomy using conventional instruments: An initial experience using a novel technique. Surg Endosc. 2011;25(4):1153-9. doi: 10.1007/s00464-010-1332-3. [PubMed: 20927545].

17. Frutos MD, Abrisqueta J, Lujan J, Abellan I, Parrilla P. Randomized prospective study to compare laparoscopic appendectomy versus umbilical single-incision appendectomy. Ann Surg. 2013;257(3):413-8. doi: 10.1097/SLA.0b013e318278d225. [PubMed: 23386239].

18. Liang HH, Hung CS, Wang W, Tam KW, Chang CC, Liu HH, et al. Single-incision versus conventional laparoscopic appendectomy in 688 patients: A retrospective comparative analysis. Can J Surg. 2014;57(3):E89-97. doi: 10.1503/cjs.023812. [PubMed: 24869622]. [PubMed Central: PMC4035411].

19. Kang KC, Lee SY, Kang DB, Kim SH, Oh JT, Choi DH, et al. Application of single incision laparoscopic surgery for appendectomies in patients with complicated appendicitis.J Korean Soc Coloproctol. 2010;26(6):388-94. doi: 10.3393/jksc.2010.26.6.388. [PubMed: 21221238]. [PubMed Central: PMC3017973].

20. Kim HO, Yoo CH, Lee SR, Son BH, Park YL, Shin JH, et al. Pain after laparoscopic appendectomy: A comparison of transumbilical single-port and conventional laparoscopic surgery.J Korean Surg Soc. 2012;82(3):172-8. doi: 10.4174/jkss.2012.82.3.172. [PubMed: 22403751]. [PubMed Central: PMC3294111].

21. Pandey R, Mehra B, Keisham R. Evaluation of post operative pain and cosmetic outcome between single incision laparoscopic appendectomy and conventional three port laparoscopic appendectomy: A randomized clinical trial. EJPMR. 2016;3(4):203.

22. Lohsiriwat V, Lert-akyamanee N, Rushatamukayanunt W. Efficacy of pre-incisional bupivacaine infiltration on postoperative pain relief after appendectomy: Prospective double-blind randomized trial. World J Surg. 2004;28(10):947-50. doi: 10.1007/s00268-004-7471-8. [PubMed: 15573244].

23. Weiss HG, Brunner W, Biebl MO, Schirnhofer J, Pimpl K, Mittermair C, et al. Wound complications in 1145 consecutive transumbilical singleincision laparoscopic procedures. Ann Surg. 2014;259(1):89-95. doi: 10.1097/SLA.0b013e31827b7818. [PubMed: 23426333].

24. Assali S, Eapen S, Carman T, Horattas S, Daigle CR, Paranjape C. Singleport Laparoscopic Appendectomy: Beyond the Learning Curve: A Retrospective Comparison With Multi-port Laparoscopic Appendectomy. Surg Laparosc Endosc Percutan Tech. 2018;28(5):291-4. doi: 10.1097/SLE.0000000000000546. [PubMed: 29847482].

25. Ibrahim MF. Single Incision Laparoscopic Surgery (SILS) appendicectomy as alternative surgical procedure in diagnosis and treatment of acute appendicitis. WLH. 2010:1-14. 